\title{
Blogs - The New Source of Data Analysis
}

\section{Michael Jones and Irit Alony \\ School of Management and Marketing, Faculty of Commerce, University of Wollongong, Wollongong, Australia}

\section{mjones@uow.edu.au; la120@uow.edu.au}

\begin{abstract}
Blogs are a new and intriguing form of communication and personal expression. Researchers are only just beginning to realise the value that these media present as sources of data for research. This paper begins to unveil the untapped potential that the blogosphere provides for research. The paper begins by introducing blogs, explaining their evolution and the important role they play in society.

A major contribution to knowledge comes from the paper's analysis of the motivation behind blogging - providing a framework of seven different motivational schemes. Building on this, the paper explores why blogs are a valuable and reliable source of data for analysis. The paper illustrates how blogs can be used for analysis, highlighting the advantages and disadvantages of their use. The paper concludes with a brief note on some of the ethical considerations of using blogs for research.
\end{abstract}

Keywords: Blogs, Blogosphere, Qualitative Research, Research Methods, Data Analysis.

\section{Introduction}

Individual expression has evolved into a new and useful form. Blogs have become an important form of emotional and informational release for a growing proportion of the population. Commencing with an overview of the development of the blog, this paper takes the reader through a journey of understanding, explaining why blogs are important, how they work, who writes, and who reads them. Ultimately, the paper explains how blogs can be used for research, the opportunities of using blogs as research input, as well as the problems this usage involves.

\section{What is a Blog?}

Blogs are commonly described as frequently modified web pages in which dated entries are listed in reverse chronological sequence (Bortree, 2005; Buckingham \& Willett, 2006; Herring, Scheidt et al. 2005; Kelleher \& Miller, 2006; Schmidt, 2007). Moreover, blogs are an amalgam between a diary, a web site, and an online community (Embrey 2002). Typically, they are personal journals

Material published as part of this publication, either on-line or in print, is copyrighted by the Informing Science Institute. Permission to make digital or paper copy of part or all of these works for personal or classroom use is granted without fee provided that the copies are not made or distributed for profit or commercial advantage AND that copies 1) bear this notice in full and 2) give the full citation on the first page. It is permissible to abstract these works so long as credit is given. To copy in all other cases or to republish or to post on a server or to redistribute to lists requires specific permission and payment of a fee. Contact Publisher@InformingScience.org to request redistribution permission. which are published online, and are frequently updated with links to similar and related topics, often from other bloggers. This interconnection of blogs is known as 'the blogosphere'.

The term 'blog' comes from an early description of the medium as a log or diary which is published on the internet, hence the contracted term 'blog' from Web Log. The original term - Web Log 
- was coined by John Barger, editor of the Robot Wisdom blog in 1997 (Blood, 2000). The contracted term blog was first pronounced by Peter Merholz in 1999 (Merholz, 2002). Blogging began its incarnation in the late 1990s as a means for individuals to publish simple, online personal diaries (Williams \& Jacobs, 2004) as an alternative to the personal home-page (or web-page) - a popular form of internet-based self expression at the time. It has since evolved into a "killer app' that has the capacity to engage people in collaborative activity, knowledge sharing, reflection and debate" (Hiler, 2002, p. 4). Blogs have developed more through convenience than through design. As a result, blogs are akin to other forms of human communication: they are unstructured, organic and opportunistic (Williams \& Jacobs, 2004).

Blogs enable, in their writers, a freedom of expression which may not be as readily available in other media (Hull, 2007). They cover a wide range of subject areas, both serious and fun, and attract an eclectic array of readers (Hull, 2007). One of the values of blogs lies in its versatility. Schmidt (2007) lists various types of blogs, including: political blogs, corporate blogs, expert blogs, and personal knowledge blogs. There are also educational blogs, creative writing blogs, journalism blogs, medical blogs, drug blogs, abortion blogs, car blogs, travel blogs, and the list continues. In fact, any subject which generates interest among a reasonably sized group of people has the potential to become a blog. In addition, a blog is not necessarily an individual enterprise (Williams \& Jacobs, 2004), as shown by the existence of group blogs such as: "family blogs, community blogs, and corporate blogs". Other blogs are defined by their content: 'WarBlogs' (a product of the Iraq War), and 'LibLogs' (library bogs) (Williams \& Jacobs, 2004). However, most blogs tend to be personal journals by single authors (Qian \& Scott, 2007; Schmidt, 2007).

The proliferation of blogs over the internet is explosive. The actual count of the number of blogs present on the internet at any one time varies and is difficult to estimate. Rebecca Blood, who has published a comprehensive history of blogging, states that in 1999 only 23 blogs were known to exist (Blood, 2000). There has since been an exponential growth in blog development. 'Technorati', one of many blog search engines, measures this growth, and in March 2006 counted 30 million bloggers on the internet. In July, 2007 this number increased to 90 million (Pedersen \& Macafee, 2007). This rate of increase is plotted in Figure 1. 'Technorati' estimate there is a doubling of blogs every six months (Macdonald \& Ounis, 2006). Flynn (2006) states that a new blog is opened every second.

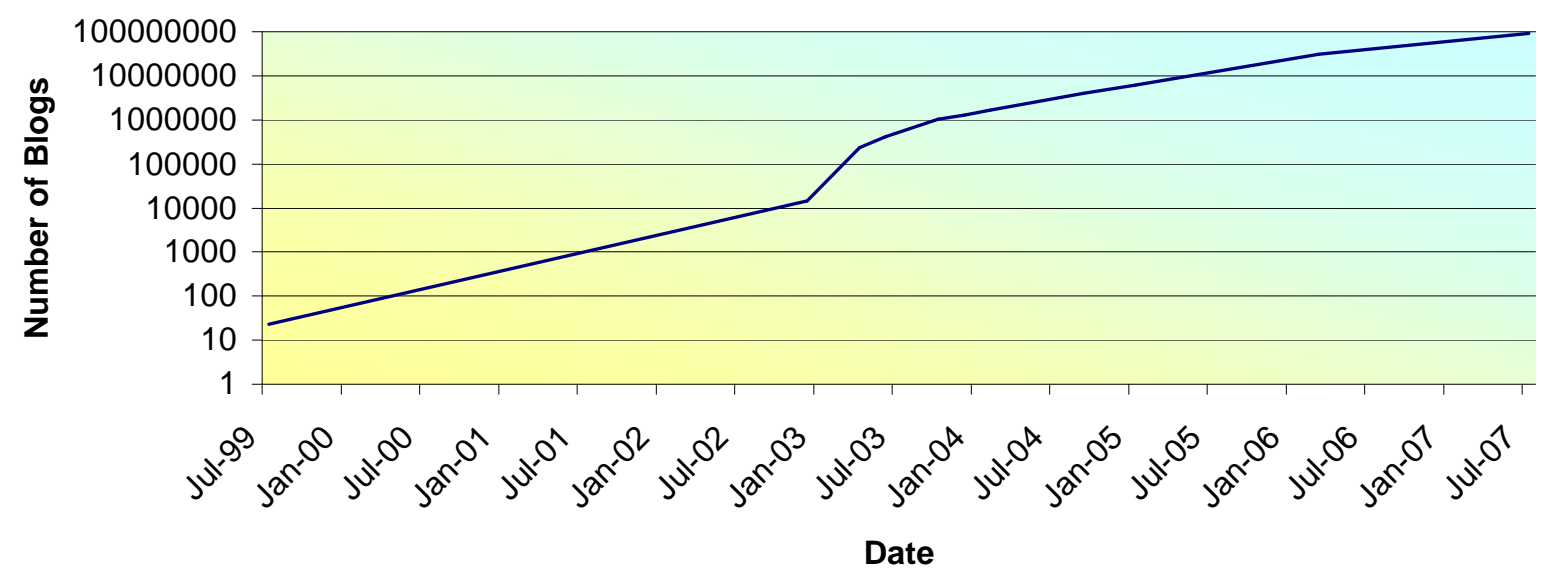

Figure 1. The increase in numbers of blogs - scale is logarithmic. Compiled from (Blood, 2000; Bar-Ilan, 2005; Pedersen \& Macafee, 2007) 
A number of factors contribute to this proliferation of blogs. Firstly, the increased accessibility and ubiquity of the internet creates an increased opportunity for people to record and broadcast their personal thoughts and opinions (Wang, Fix, \& Bock, 2005). Secondly, social software is increasingly becoming available which assists bloggers in creating a blog. This technology therefore permits people of almost any skill level to create a blog. The technologies also allow many deviations and additions, including variations such as: "Wikis, Moodle, collaboration systems, shared spaces, and virtual worlds, where people interact, exchange, collaborate, or network" (Wang et al., p. 1). Barriers to entry for the blogger are small; therefore anyone with an opinion can launch themselves on the world. "A blogger needs only a computer, Internet access, and an opinion. It also helps to have a personal obsession and total confidence in your own voice" (Rosenbloom, 2004, p. 31). Thirdly, there is also an increased acceptance of blogs both as a communication tool and as a source of information. What was once considered a personal obsession (Rosenbloom, 2004) is now mainstream and accepted, even supported by the general public.

\section{Blog Writers, Blog Contents, and Motivation}

Kumar, Novak, Raghavan and Tomkins (2004) studied 1.3 million bloggers in an endeavour to profile the blogosphere. They found that $75 \%$ of bloggers were aged 16-24 years. They also found that bloggers tended to focus on core themes within their age groups. Table 1 illustrates these findings and groupings of interests, found in US blogs.

In addition to covering a large spectrum of interests in their blogs, bloggers take a very narrow, and in-depth, focus on the issues that interest them. Bloggers can work faster and communicate in greater depth than can regular media. For instance, bloggers were the first to alert the world to the Iraqi prisoner abuse (Rosenbloom, 2004), and the role of bloggers played a large part in the recent resignation of US Senator Trent Lott, due to his ill-placed comments (Yang, 2007). Blogs, therefore, have an underestimated level of power and influence. At the same time blogs have the ability to dramatically decrease "the power and authority of the traditional general-interest intermediaries, notably newspapers, magazines, and broadcasters" (Rosenbloom, 2004, p. 33).

Table 1. Classification of blog types according to age and interests. From (Kumar et al., 2004, p. 37)

\begin{tabular}{|l|l|l|l|}
\hline \multicolumn{1}{|c|}{ Age } & \multicolumn{1}{|c|}{ Blog Types } & \multicolumn{1}{|c|}{ Themes } \\
\hline $1-3$ & 0.5 & Diary & $\begin{array}{l}\text { Mommy, Daddy, Nappies, Catnip, Purring, } \\
\text { Playing, Mice }\end{array}$ \\
\hline $13-15$ & 3.5 & Diary, Interests (Celebrities) & $\begin{array}{l}\text { Jeremy Sumper, Emma Watson, TV, Web } \\
\text { desgining, Mall }\end{array}$ \\
\hline $16-18$ & 25.2 & Diary, Interests (TV shows) & $\begin{array}{l}\text { Dream Street, High school, Talking on the } \\
\text { phone, Brave New Girl, Drama club }\end{array}$ \\
\hline $19-21$ & 32.8 & Diary, Interests & Dorm, College life, My tattoo, Pre-med \\
\hline $22-24$ & 18.7 & $\begin{array}{l}\text { Interests (Entertainment), } \\
\text { Diary }\end{array}$ & $\begin{array}{l}\text { Dumbeldore's army, Long Island iced tea, bar } \\
\text { hopping, fraternity, He-Man }\end{array}$ \\
\hline $25-27$ & 8.4 & $\begin{array}{l}\text { Interests (Various), Diary, } \\
\text { Consumers' Critique }\end{array}$ & $\begin{array}{l}\text { Catherine Wheel, Dive bars, Grad school, } \\
\text { Good beer }\end{array}$ \\
\hline $28-30$ & 4.4 & Interests (Various), Diary & Hal Hartley, geocaching, Motherhood, SQL \\
\hline $31-33$ & 2.4 & $\begin{array}{l}\text { Diary (Family), Interests, } \\
\text { Consumers' Critique }\end{array}$ & $\begin{array}{l}\text { My kids, Parenting, Doctor Who, geocaching, } \\
\text { Good eat, Herbalism }\end{array}$ \\
\hline $34-36$ & 1.5 & Diary (Family), Interests & $\begin{array}{l}\text { Parenting, Role-playing games, Bicycling, } \\
\text { Shamanism, Thelema, tivo }\end{array}$ \\
\hline
\end{tabular}




\begin{tabular}{|l|c|l|l|}
\hline \multicolumn{1}{|c|}{ Age } & \multicolumn{1}{|c|}{ Blog Types } & \multicolumn{1}{c|}{ Themes } \\
\hline $37-45$ & 1.6 & Interests & $\begin{array}{l}\text { Pagan, Gradening, Star Trek, Hogwarts, Ma- } \\
\text { chintosh, Zen, Tarot }\end{array}$ \\
\hline $46-57$ & 0.5 & $\begin{array}{l}\text { Interests, Consumers' Cri- } \\
\text { tique }\end{array}$ & $\begin{array}{l}\text { Science fiction, Travel, Cooking, History, Po- } \\
\text { etry, Reading, Walking, Hiking, Wine }\end{array}$ \\
\hline$>57$ & 0.2 & Interests & Death, Cheese, Photography, Cats, Poetry \\
\hline
\end{tabular}

\section{Motivations to Blog}

A relatively large amount of research has been invested in an effort to discover why bloggers blog (Bar-Ilan, 2005). As the growth trends of blogging indicate, research about bloggers is still emerging and requires frequent updates. Nonetheless, motivations for blogging remain stable over time, as blogging satisfies basic human needs. We do not distinguish between motivations to open blogs and motivation to maintain blogs, as no such distinction appears in literature, however we are aware that the two may not be identical. Further research on this subject is required.

Our analysis revealed seven needs blogging answers: (1) need for self expression, (2) need for recognition, (3) need for social contact, (4) need for introspection, (5) academic needs for knowledge and interests, (6) need for documentation, and (7) need for artistic activity. These motivations are exhibited in Figure 2 below.

Motivation to Blog

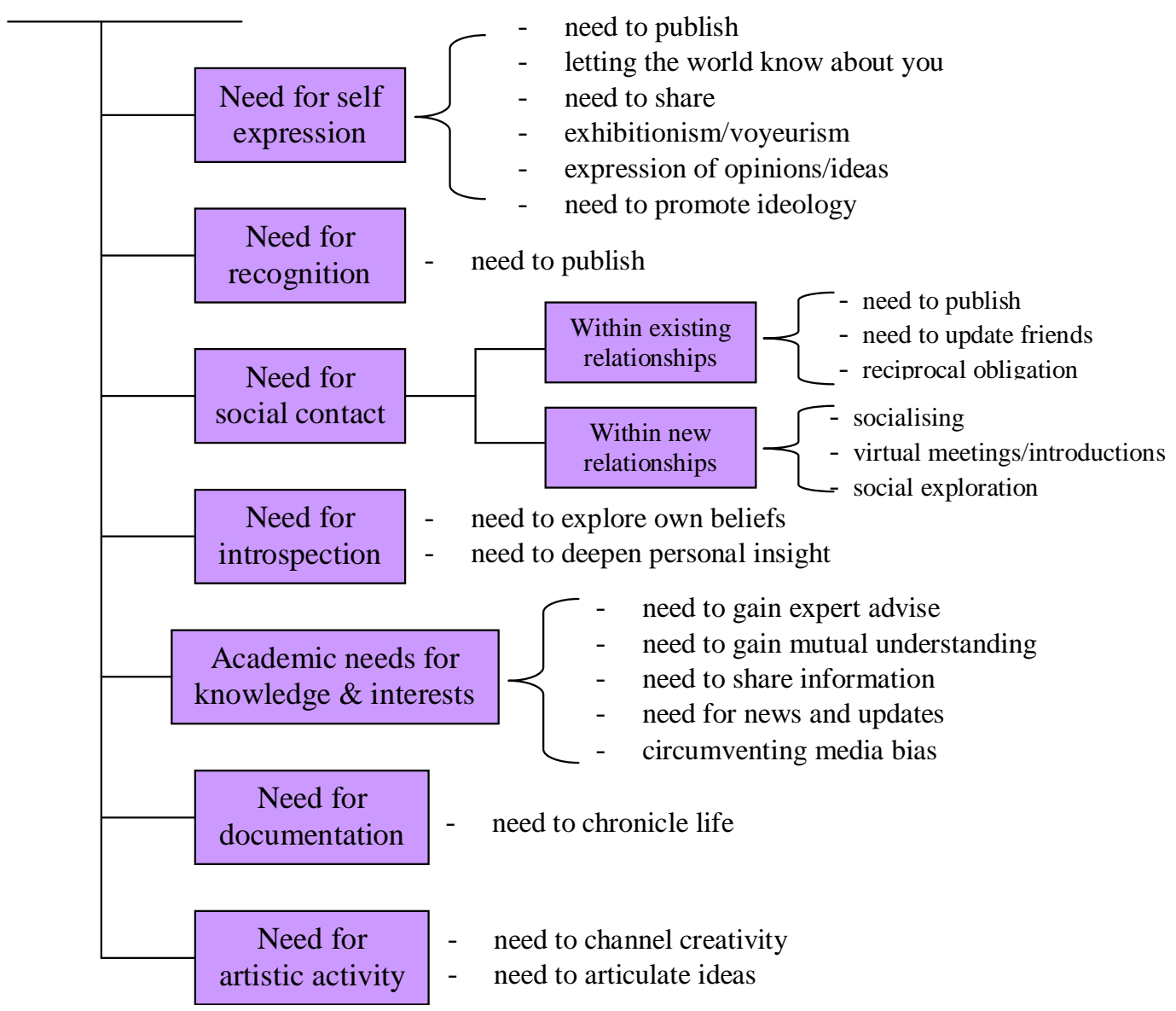

Figure 2. The various schema of motivation to blog. 


\section{Need for Self Expression}

Self-expression is a basic and strong human need, which has characterised humanity from the dawn of human existence. This need leads individuals to share their opinions, thoughts, experiences and views with others. This need for expression is part of an individual's "need to publish", identified by Graham (2002). The audience for this self-expression may be either familiar to the blogger, or anonymous.

This need for self expression is a recurring theme in most blog-motivation research, and encompasses various topics for self-expression. One major topic is 'the inner self" - "letting the world know about you" (Turgeon, 2004) as well as "expressing deeply felt emotions" (Nardi, Schiano et al. 2004). This expression provide a means of catharsis and a type of relief valve permitting people to express their feelings in a safe environment - with the hope that someone, somewhere out there, will understand them or their problem. "Blogs helped explore issues the authors felt "obsessive" or "passionate" about. Blogs gave people a place to "shout," or express themselves by writing to an audience of sometimes total strangers, sometimes their best friends and colleagues and family members" (Nardi, Schiano, Gumbrecht, \& Swartz, 2004, 44). Frequent examples of this motive are blogs by people who are suffering an illness or who have significant member of their family suffering and illness, as well as bloggers telling the story of a traumatic experience. Exposure of the painful issue is a motivator in itself. In these cases, blogs also provide an important channel of support and mutual condolence. As explained by Jacobs: "The very interactive nature of blogging makes it innately supportive of both exhibitionistic and voyeuristic behaviours and ensures its continued growth at least in the immediate future" (Jacobs, 2003, p. 2).

Another major topic expressed in blogs is the blogger's opinions and ideas. The blog then serves as a platform "to embrace a cause, or to promote an ideology" (Anastasi \& Cochrane, 2006, p. 1), to express the blogger's idea of the truth (Lasica, 2002), and to provide commentary and opinions: "Blogging provided an outlet for expressing a point of view on topics the authors considered much more than just chatter" (Nardi et al., 2004, p. 44).

\section{Need for Recognition}

The need for recognition and acknowledgement of an individual explains why bloggers publish even to an anonymous audience. As described by Williams and Jacobs, a blog is 'a means of reaching a wider audience; an unknown mass of 'netizens', ready and willing to respond to the opinions and commentaries of bloggers' (2004, p. 234). Graham's "need to publish" (2002) also applies to this need, as well as Turgeon's the need for "feeling heard, and sometimes understood" (2004). This need drives blogging which provides the blogger with feedback, which is attained through comments left by readers, as well as web-counters indicating number of visits to the webpage. Links to the blogger's web page is another sought after form of recognition, as links to a blog increase its exposure to potential readers.

\section{Need for Social Contact}

This is another repeating theme in literature for motivations to blog. This need encompasses many sub-types of motivation.

\section{Social Contact within Existing Relationships}

Blogs are used to update friends, family and acquainted about the bloggers' life events. Graham (2002) reported this as motivation to reduce email driven spam, since updating by email creates a large volume of email traffic. In addition, maintaining contact with existing friends is a motivator to continue blogging activity, similar to what Meyer and Allen (1991) term normative commitment. This is where the blogger continues to blog because in stopping they feel they would be 
letting others in their blog community down. A great deal of the self perpetuation apparent in the blogosphere results from shared feelings of obligation to read and respond to 'friends' blogs and this reciprocal cycle of felt obligation in part sustains the blogosphere.

\section{Social Contact within New Relationships}

Turgeon (2004) explains it as 'meeting people isn't easy', thus suggesting to use a blog to make new acquaintances. Blogs also allow learning more about others, and deepening one's understanding of 'human nature'. Nardi et al. (2004) refer to this need as the need for forming and maintaining community forums. Meeting new people over the internet enables meeting with individuals with whom the blogger has pre-supposed commonalities, as the interests and opinions of a blogger are embedded in the way they present themselves online.

\section{Need for Introspection}

Curiosity about oneself also drives bloggers to blog, as exploring their own beliefs, views and reactions provides the blogger with better insight about themselves. This need was described by Turgeon as 'getting to know yourself' as well as deepening the understanding of human nature (2004), and by Graham in general as 'explore and experiment' (2002).

\section{Need for Information and Skill Development}

The proliferation of blogs discussing hobbies and areas of interests is demonstrated in Table 2. These blogs attract individuals with common interests to the same blogsphere, where they share and collect information about these areas of interest (Turgeon, 2004). These blogs enable bloggers the opportunity of being occupied with their areas of interest, and provides them with greater expertise in these interest areas.

Blogs also enable an 'underground' culture of information sharing. Many individuals question the truthfulness or objectiveness of the information available to the public through official channels, from news and events to medical remedies. Bloggers then strive to portray current events in a less prejudiced way: "Even as their comments arouse controversy and scepticism, they've [bloggers] added depth to the way the related issues are discussed and reported, especially by the traditional mass-market media" (Rosenbloom, 2004, p. 32). As Pedersen and Macafee (2007, p. 1484) put it: "they were redressing the distortions of the media". When Pedersen and Macafee asked one of their respondents why he blogged, he responded: "Rupert Murdoch" (2007, p. 1484). Although the credibility of information on blogs is often questioned (Yang, 2007), some blogs are "created by experts in their subject field to provide news and updates and sometimes to create a community of interest around the blog" (Clyde, 2006, p. 43).

In addition, bloggers reported the need to 'learn web-publishing' as a motivator for blogging (Graham, 2002). This development of expertise may not necessarily be for commercial or vocational needs, but develops the bloggers' skills. 
Table 2. Bloggers interests - concurrent themes. Modified from (Kumar et al., 2004, 37)

\begin{tabular}{|l|l|l|l|}
\hline \multicolumn{1}{|c|}{ Cluster Label } & \multicolumn{1}{|c|}{ Interest expressed } & \multicolumn{1}{c|}{ Age Group } & \multicolumn{1}{c|}{ Location } \\
\hline New Age & $\begin{array}{l}\text { Zen, Metaphysics, Quantum physics, Bud- } \\
\text { dhism, Philosophy, Theology }\end{array}$ & $25-36$ & Seattle \\
\hline Body Art & Tattoos, Body Art, Body Piercing & $25-39$ & Australia \\
\hline Coffee & Coffee, Caffeine, Espresso & $28-30$ & Seattle \\
\hline Russian Hackers & $\begin{array}{l}\text { Java, Programming, Linux, FreeBSD, } \\
\text { Hacking, Open Source }\end{array}$ & $22-39$ & Russia \\
\hline
\end{tabular}

\section{Need for Documentation}

The need to document ones life is also familiar to mankind since the early days of humanity. Blogs provide a convenient platform for documenting ones life as it unfolds. The nature of a blog enables dated entries of the blogger's experiences as well as photos, links and videos. Documenting one's life is recognised by Nardi et al. (2004) as a major motivator to blog.

\section{Need for Artistic Outlet}

Bloggers use their blogs to channel their creativity or to find an audience for their scholarly expression. Articulating ideas through writing (Nardi et al., 2004) is another motivator for blogging. While a blog does not necessarily need to be a "writing" blog (photoblogs are a common form of blogs), the activity of writing is an attraction in itself for bloggers. It provides bloggers with an opportunity to gain experience in writing, and the exposure to other writing styles enriches this experience.

Blogs provide an opportunity for individuals who wish to bring out aspects of their personality which are not dominant in their real life. They are thus able to construct an identity that they are happy with and they feel reflects an important part of themselves for others to see (Anastasi \& Cochrane, 2006).

The motivation to blog has a strong influence on the blog's contents. It is therefore expected blogs will contain both genuine and biased contents. These biases have to be taken into account, in order to use blogs for research. The next section examines these influences and biases.

\section{Blogs as Data Source}

Blogs present a tempting source of qualitative data. This section explores the benefits and the problems involved with using a blog as a data source for research.

\section{Benefits}

\section{Convenience and ease of access to codified data}

One of the major problems associated with collection of qualitative data is the synchronous, timeconsuming method of collection. Typically, qualitative data are collected via interviews, observation, or focus groups. These methods demand the mutual availability of both the subject(s) and the interviewer. In addition, the interviewer has to maintain a high level of focus and sensitivity throughout the collection in order to record the various cues presented during data collection. This poses additional constraints on the act of qualitative data collection. Apart from data collec- 
tion, data also needs to be codified for analytical purposes, which in turn requires more time and resources.

Blogs, which are readily available in a print format, offer an immediate availability of rich, codified data in an efficient package pre-prepared for analysis. Blogs do not require synchronization between the researcher and the subject, and so are more convenient and less time and resource demanding. Another source of convenience can come from the content of the blog which is often categorised by the blogger according to their assignment of topic, mood, or motivation. This enables faster and easier access to information of greatest value.

\section{Richness and depth of information available}

Blogs provide rich and deep personal accounts. The richness of this data is derived from the longitudinal nature of a blog, as well as the connectivity between issues discussed in the blog and links the blogger may provide relating to the issue. The depth is a result of the freedom in writer's topic selection. Since bloggers choose their own topics, it is natural their choices reflect their areas of interest. Their writing of these issues is opinionated and often unbiased, as they are free to express their own views, expecting no tangible consequences. In addition, as the need for introspection is one of the motivator to blog, personal accounts in blogs are typically candid and genuine, providing valuable insight into the issues present on individuals' minds.

\section{Unbiased by research process}

Blog data is by nature primary data which is not subject to the influence or interference of the researcher. It is therefore not fallible to many of the weaknesses and biases of many other forms of data collection, whether face-to-face or remotely collected. Typical of these influences is that of the Hawthorne Effect (Hartley, 2001). The Hawthorne Effect in particular causes respondents to provide or accentuate data they think will please the interviewer. Blog contents, however, are unaffected by the researcher, assuming that the blogger is not aware of the research when writing.

\section{Sample constraints - Variety of subjects}

The data sample available through blogs may be biased, particularly due to the medium type which is a pre-requisite for bloggers. A blogger needs to have an attraction to writing in general, and to writing over a computerized medium in particular. It is expected that 'techno-phobes' will not be represented in the blogging population, in addition there will be an uneven representation in older age groups and in less developed economies. However, as discussed above, blogging is proliferating at unprecedented rates in the population. It is also expected that with the growth of technologically-native population, blogs will become as common and ubiquitous as the mobile phone. This abundance of personal data and its efficient availability means that there is a virtual font of data available to researchers on a wide and growing variety of subject areas.

Research on the different types of bloggers is still developing, however an increasing section of the worlds' population are taking to this activity. Further research to draw on the various types of bloggers is required to better understand the demographics available in this medium.

\section{Problems}

\section{Impurity of data}

Blogs are not always well written, succinct, concise or elaborate. The data offered by blogs can be difficult to investigate as they may contain errors, poor phrasing, or lengthy and irrelevant content. However, this problem is not limited to blogs, and exists in most types of qualitative data. Some interviewees are more articulate than others, some are more passionate. Individuals will 
also have varying competence with writing and language skills. The irrelevance of data is also not a problem unique to blogs. It can contribute to problems with subject observation and document analysis. Therefore, the analysis of blog content, as with many other types of analysis, has to be either treated as indicative, or triangulated with other data sources.

Blogs can provide an added option for confirmation and consistency. With a blog it is always possible to interact with the blogger to ask for clarification. This is common practice within the blogging community, and often taken as a complement by the blogger.

\section{Reliability and validity of data - biases}

Unlike errors or misinterpretations discussed above, blogs also present biases stemming from social endorsement. This important motivator makes bloggers likely to avoid alienating their readers, and attempt to appeal to them.

Attaining exposure and readers is another goal of bloggers, which may lead them to sensationalise their issues, or even create fictitious issues to attract an audience. For example, a blogger may embellish their experiences to present a more interesting and attractive story for the readers, or they may bias their topics to what they feel brings larger reading audience.

The researcher will need to account for these potential biases, however they may not be different to biased autobiographies or other forms of self-accounts. In addition, the blogsphere has the potential to limit these biases, since social interactions resulting from blog interactions often transfer into the real world. This imposes a certain level of honesty.

Opinions expressed in blogs offer a level of reliability which is not greatly different from other methods of data collection.

\section{Reliability and validity - deception}

There are no means to prevent fictitious blogs. Individuals can pretend to be of another social status, another educational level, another age, even another gender. While most blog templates provide the option to make such details available, bloggers can choose not to do so, or to post fictitious data. Researchers have no means to verify or validate such self-reported details.

However, since one of the strong drivers for blogging is the need for recognition, individuals are more likely to expose their true details. Deceptive and fictitious identities do not satisfy this need and most healthy individuals would not be able to sustain it over time. A method researchers can use to verify these blog details is to restrict blog samples to only those which have endured over time, i.e. those over a year 'old'.

In addition, self-expression is a strong motivator for bloggers, which drive them to expose their true-self. Therefore, although blogs may have biased content, they also contain genuine accounts. This is no different to other self-evident data.

Another strong need answered by blogging is the need for social contact. Many bloggers end up meeting face-to-face. These meetings are often documented and reflected upon in the blogs themselves. Some blogospheres have group events where many bloggers of the same blogosphere meet. These meetings are also reflected upon in the blogs. Evidence of such meetings enables researcher to verify, to some degree, the credibility and reliability of self-reported details, since the likelihood of deception by many individuals is lower. In addition, fictitious bloggers tend not to meet with other bloggers.

This is not to say that deception or exaggeration does not exist in blogs. However, simple measures can be taken by researchers to reduce the extent of this bias. Deception is not common, and 
is not sustainable over time. Most of the motivators for blogging support genuine and truthful self-accounts. Blogs therefore provide access to data usable for research.

\section{Type of Research}

The most reliable information available over blogs is individual personal accounts. This presents some useful data source for a first level analysis. Data can be analysed for use in a pilot study to determine key concepts, develop a research question, or simply a primary level of analysis. In addition, the use of blogs can provide a conceptual analysis for use in quantitative research for survey design.

Conducting research using blogs serves various types of questions. Appropriate types of research methods are discussed below.

\section{Content Analysis}

An obvious way to use blogs is to analyse their content on a certain topic. This type of research explores the various themes raised on that topic. Blogs provide an insider view of what bloggers feel and think about various social issues. This content is useful as primary data for publication or used for comparison with other sources, either other blog sites or other empirical data. For example in preparation for this paper the authors did a quick analysis of the following social problem: 'What do teenagers think about smoking' and 'what is their opinion of anti-smoking campaigns'. Data were sought from three countries: Australia, Malaysia, and the USA. After cursory investigation sufficient information was found which would permit a cross-cultural analysis of this problem. As is discussed above, there are many issues that bloggers discuss in detail. The potential for social research using blogs as an empirical source of data is only limited by the time taken to collect and analyse the data.

Public interest can also be estimated using blogs. The content of blogs is a reflection of the interest areas of the writers. However, different topics generate different levels of interest within the reading community. The number of comments, as well as their content and length can indicate that level of interest. Comparison of the number of comments generated by different topics can indicate the level of public interest in these topics, for example, comparing the number of comments generated by topics of a sexual nature as opposed to a political nature. Or the activity generated in a political campaign, and to which party most commentary is directed. An assumption has to be made in such studies that the intent of every post is to generate as many comments as possible.

\section{Discourse Analysis}

Bloggers are often articulate individuals, some with highly developed writing skills, therefore their choice of words and the language used can provide insight into the value and depth of a particular topic. Access to blogs can, in some areas, provide an abundance of material for analysis, comparison and discussion.

\section{Trend Analysis}

Another style of research can be to determine the level of interest that a blog community, or various communities, hold in a certain issue. This type of research operates on the assumption that bloggers, using their blogs as a voluntary medium of expression, will only write about issues in which they have a direct interest. Therefore, the fact that a topic has been mentioned in a blog suggests it is an area of interest. Looking in an existing blogosphere, researchers can compare the number of posts mentioning a certain topic. For example, a comparison of the number of blogs 
discussing the recent election results in Australia compared to other topics discussed in the same blogosphere can indicate the level of public interest in national politics.

\section{Longitudinal Studies}

Longitudinal analyses can also be run to determine various social phenomena. For instance variations in blog uptake may indicate various characteristics in society. How do the growth rates compare in a society where the youth are engaged in less leisurely activities compared to a society where there is a larger amount of social freedom in the youth - for example Israel compared to France. In addition, longitudinal research can indicate changes in social trends. For example: are the youth focussing more or less on personal health issues like AIDS and drugs? Are family values being reflected more or less in blogs? The growth trends of a blogosphere can indicate similar trends in society. The nature of the blog can indicate the motivation for its opening: personal journal, business or other. For example, a significant growth in personal blogs dealing with war stories in a war zone can indicate an increased need to communicate and document. Increased personal blog activities of teenagers during school holidays can indicate not only increased leisure time, but also perhaps a lack of ability to socialize outside the virtual world. A similar trend analysis could be used to compare the growth in blogs to the growth and availability of IT resources in host countries.

\section{Participant Observation}

Researchers can also adopt a participatory stance - a pseudo ethnography or phenomenology - to learn how comments and members are generated. A participatory method of blog-research involves joining a blogosphere and participating in various activities (such as commenting to others) and then testing various reactions to various topics, opinions, and behaviours. For example, the type of readers the blog attracts with different topics

\section{Conclusion and Further Issues}

Technology has taken over many aspects of our lives and research is no exception. Blogs provide a novel and rich resource for researchers to acquire empirical data on a wide range of topics. The marked growth in the use and acceptance of blogs can only enhance its viability as a research instrument. Added to this, blog-based research provides many avenues of investigation; from pure sociological to anthropological and psychological; and from analysis of personal insight to understanding the strategic direction of the corporate sector.

This paper classified seven types of motivations which satisfy needs in bloggers promoting their desire to blog: need for self expression, need for recognition, need for social contact, need for introspection, academic needs for knowledge and interests, need for documentation and need for artistic activity. These needs dictate the content and reliability of blogs. The needs for selfexpression, documentation, and introspection suggest genuine and candid personal accounts. The need for recognition suggests reporting of true characteristics of the blogger. The need for social contact, as well as reported social interactions resulting from blogging suggest imposed honesty on self-reported accounts. The sustainability of a blog over time provides an indication of the authenticity of self-disclosed opinions and events.

One consideration not addressed in this paper is the issue of ethics with regard to blog or cyber research. As this type of research is still relatively new, little has been tested with regards to ethics. However there seems to be two distinct schools of thought (Bassett \& O'Riordan, 2002). On one side of the issue researchers consider blog research as being similar to any sociological research, and as such participants should be consulted and their approval should be sought. The 
other approach sees these resources which are freely available on the internet, which is a public domain, as licence free (apart from copyright) and can be studied and reproduced.

Both of these stances are problematic. The population of the blogosphere is large, and many of its inhabitants are anonymous. It would be difficult, if not impossible in some circumstances, to contact and gain approval from a large proportion of the sample. The second argument also presents problems. Firstly, as has been discussed above when we consider the reasons why people blog, people often open up their hearts and minds through their blogs, and it is unfair, if not dishonest, to analyse these personal reflections without permission. Secondly, abuse of this medium may result in it changing to the dissatisfaction of both blogger and researcher. It is therefore imperative that researchers take steps to preserve the open character of this medium.

To make better use of blogs for research purposes, they need to be better understood. This calls for further research about blogs. For example, do the blogs have a life cycle? What are the differences in content, frequency, writing quality and motivations along the life cycle of a blog? To increase the reliability of data available on blogs, further research is required to uncover the characteristics of the fictitious blog, such as it life span, number of reported social contacts, and interactions with other bloggers. To better understand bias sample in blogs, further research is required to classify the types of individuals maintaining long term blogs, as well as the weighting of the different motivations answered by blogs and driving the continuous use of blogs.

Blogs provide an excellent avenue for research of various kinds. We predict that the growth in the utilisation of this resource will continue to grow exponentially over the next decade or two. The potential for researchers for tapping into this resource is truly profound.

\section{References}

Anastasi, J., \& Cochrane, S. (2006). Are they too old to learn? Exploring the barriers to using weblogs in demystifying the information literacy experience for mature age undergraduate students. Networked Learning, 1-9.

Bar-Ilan, J. (2005). Information hub blogs. Journal of Information Science, 31(4), $297-307$.

Bassett, E. H., \& O'Riordan, K. (2002). Ethics of Internet research: Contesting the human subjects research model. Ethics and Information Technology, 4(3), 233-249.

Blood, R. (2000). Weblogs: A history and perspective. Rebecca's Pocket Retrieved 01 December 2007, from http://www.rebeccablood.net/essays/weblog history.html

Bortree, D. S. (2005). Presentation of self on the Web: An ethnographic study of teenage girls' weblogs. Education, Communication, and Information, 5(1), 25 - 39.

Buckingham, D., \& Willett, R. (Eds.). (2006). Digital generations: Children, young people, and the new media. Routledge.

Clyde, L. A. (2006). Teacher librarian. Infotech, 32(3), 43-45.

Embrey, T. R. (2002). You blog, we blog: A guide to how teacher-librarians can use weblogs to build communication and research skills. Teacher Librarian, 30(2), 7-9.

Flynn, N. (2006). Blog rules: A business guide to managing policy, public relations, and legal issues. AMACOM Div American Mgmt Assn.

Graham, B. L. (2002). Why I weblog: A rumination on where the hell I'm going with this website. In J. Rodzvilla (Ed.), We've got blog: How weblogs are changing our culture (p. 242). Cambridge, MA: Perseus.

Hartley, J. (2001). Employee surveys - Strategic aid or hand-grenade for organisational and cultural change? The International Journal of Public Sector Management, 14(3), 184-204. 
Herring, S. C., Kouper, I., Paolillo, J., Scheidt, L. A., Tyworth, M., Welsch, P., et al. (2005). Conversations in the blogosphere: An analysis "from the bottom up". Information, Technology \& People, 18(2).

Hiler, J. (2002). Blogs as disruptive tech - How weblogs are flying under the radar of the content management giants. Internet World. Retrieved 01 December, 2007, from http://www.webcrimson.com/ourstories/blogsdisruptivetech.htm

Hull, D. (2007). Blogging between the lines. American Journalism Review, Dec 06/Jan 07, 62-67.

Jacobs, J. (2003). Communication over exposure - The rise of blogs as a product of cybervoyeurism. Australian and New Zealand Communication Association Designing Communication for Diversity, Brisbane.

Kelleher, T., \& Miller, B. M. (2006). Organizational blogs and the human voice: Relational strategies and relational outcomes. Journal of Computer-Mediated Communication, 11, 395-414.

Kumar, R., J. Novak, J., Raghavan, P., \& Tomkins, A. (2004). Structure and evolution of blogspace. Communications of the ACM, 47(12), 35-39.

Lasica, J. D. (2002). Blogging as a form of journalism: Weblogs offer a vital, creative outlet for alternative voices. In J. Rodzvilla (Ed.), We've got blog: How weblogs are changing our culture (p. 242). Cambridge, MA: Perseus.

Macdonald, C., \& Ounis, I. (2006). The TREC Blogs06 collection: Creating and analysing a blog test collection. Department of Computing Science, University of Glasgow Scotland, UK: 8.

Merholz, P. (2002, May 17). Play with your words. Retrieved 01 December, 2007, from http://www.peterme.com/archives/00000205.html

Meyer, J. P., \& Allen, N. J. (1991). A three-component conceptualization of organizational commitment. Human Resource Management Review, 1, 69-98.

Nardi, B. A., Schiano, D. J., Gumbrecht, M., \& Swartz, M. (2004). Why we blog. Communications of the $A C M, 47(12), 41-46$.

Pedersen, S., \& Macafee, C. (2007). Gender differences in British blogging. Journal of Computer-Mediated Communication, 12, 1472-1492.

Qian, H., \& Scott, C. R. (2007). Anonymity and self-disclosure on weblogs. Journal of Computer-Mediated Communication, 12, 1428-1451.

Rosenbloom, A. (2004). The blogosphere. Communications of the ACM, 47(12), 30-33.

Schmidt, J. (2007). Blogging practices: An analytical framework. Journal of Computer-Mediated Communication, (12), 1409-1427.

Turgeon, M. C. (2004). 10 Reasons why blogging is good for you. Available at http://mcturgeon.com/blog/2004/11/24/10reasonstoblog/

Wang, M., Fix, R., \& Bock, L. (2005). Blogs: Useful tool or vain indulgence? E-Learn 2005: World Conference on E-Learning in Corporate, Government, Healthcare, and Higher Education.

Williams, J. B., \& Jacobs, J. (2004). Exploring the use of blogs as learning spaces in the higher education sector. Australasian Journal of Educational Technology, 20(2), 232-247.

Yang, K. C. C. (2007). Factors influencing Internet users' perceived credibility of news-related blogs in Taiwan. Telematics and Informatics, 24, 69-85. 


\section{Biographies}

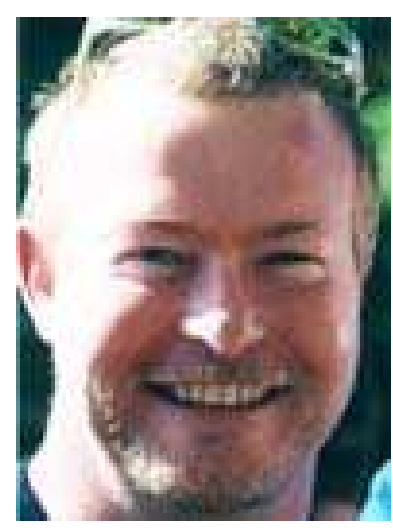

Michael Jones. BComm (hons), PhD. Michael has been an academic teaching and researching in areas of organisation, business and management for nine years. Michael has developed research interests in the following areas: organisational psychology and behaviour - looking at commitment and motivation and group dynamics. Michael is also developing research strengths in areas of qualitative analysis and has written several papers on various qualitative methodologies and methods. Michael is also interested in research areas such as knowledge management and organisational learning. Michael is also a coinvestigator on a major research project explore competitive analysis in the Australian Marine Industry.

Michael is a member of the Australia and New Zealand Academy of Management, the Australian Human Resources Institute, and the Industrial Relations Society of Australia.

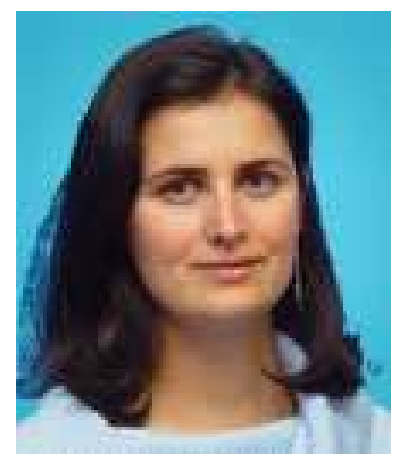

Irit Alony. BCSc; Grad.Cert. (Comp Sc.); MIS. Irit is a PhD student in the faculty of Informatics at the University of Wollongong. Her subject is the influence of organizational factors on operational decision making. She has been an academic teaching and researching in areas of information systems, knowledge management, and communication and culture for three years both at the University of Wollongong and at Central Queensland University. Irit has developed research interests in the following areas: organizational behaviour, decision making, organizational culture, and knowledge management. Irit is also developing research strengths in areas of qualitative analysis. 